\begin{abstract}
The delayed mortality rate of crab discarded during fishing operations can be under- or overestimated in laboratory holding experiments, given the unnatural conditions and the short-term duration of these experiments. To evaluate the extent to which a method affects accuracy in these estimations, we compared mortality rates established through laboratory holding with mortality inferred from a yearand-a-half long tag-return study of Dungeness crab (Cancer magister) discarded in Oregon crab fisheries. The reflex action mortality predictor (RAMP) approach, which relates reflex impairment to probability of mortality, was applied in both studies. Similar patterns in mortalityand tag return- rates with respect to fishery, sex, reflex impairment, shell hardness, and injury from the 2 studies lends support to the reliability of the laboratory-generated mortality rates. However, results suggest that mortality rates determined in captivity are likely underestimated when crab are dropped a distance of greater than $6 \mathrm{~m}$ (and potentially less) back to water. This underscores the importance of determining the contribution to mortality of variables in the capture, handling, and discard process that are not incorporated in a study to estimate mortality of discarded animals. Both studies also highlighted the significance of sample size when applying the RAMP approach to a fishery with low rates of discard mortality.
\end{abstract}

Manuscript submitted 1 June 2017. Manuscript accepted 13 December 2017. Fish. Bull. 116:126-141 (2018).

Online publication date: 26 January 2018. doi: $10.7755 /$ FB.116.1.2

The views and opinions expressed or implied in this article are those of the author (or authors) and do not necessarily reflect the position of the National Marine Fisheries Service, NOAA.

\title{
A comparison of laboratory-holding and tag- return methods for evaluating delayed mortality of Dungeness crab (Cancer magister) discarded in Oregon fisheries
}

\author{
Noëlle Yochum (contact author) ${ }^{1}$ \\ Allan W. Stoner ${ }^{2}$ \\ David B. Sampson ${ }^{1}$ \\ Craig Rose ${ }^{3}$
}

Email address for contact author: noelle.yochum@noaa.gov

${ }^{1}$ Department of Fisheries and Wildlife and

Coastal Oregon Marine Experiment Station

Oregon State University

2030 SE Marine Science Drive

Newport, Oregon 97365

Present address for contact author: Alaska Fisheries Science Center National Marine Fisheries Service, NOAA 7600 Sand Point Way NE Seattle, Washington 98115

2 Alaska Fisheries Science Center

National Marine Fisheries Service, NOAA

2030 SE Marine Science Drive

Newport, Oregon 97365

3 Alaska Fisheries Science Center

National Marine Fisheries Service, NOAA

7600 Sand Point Way NE

Seattle, Washington 98115

Mortality can result from the fishing, handling, and discard process for nontarget animals, either immediately after capture or after a delay (Benaka et al., 2014). To evaluate the mortality of discarded animals (henceforth termed "delayed discard mortality"), a variety of methods have been employed. These include the following: 1) captive-holding methods (Kennelly et al., 1990; Bergmann et al., 2001; Parker et al., 2003); 2) mark-recapture methods (Kruse et al., 1994; Watson and Pengilly ${ }^{1}$; Trumble et al., 2000); and

${ }^{1}$ Watson, L. J., and D. Pengilly. 1994. Effects of release method on recovery rates of tagged red king crabs Paralithodes camtschaticus in the 1993 Bris-
3) results from telemetric studies, including that use radio- (Raby et al., 2012; Nguyen et al., 2014), acoustic(Pepperell and Davis, 1999; Donaldson et al., 2012; Yergey et al., 2012), and satellite-tracking tags (Gallagher et al., 2014). Also used are 4) in situ net pens or cages (Diamond and Campbell, 2009; Brownscombe et al., 2015; Bower et al., 2016); and 5) in situ visual monitoring (Campbell et al., 2010; Hochhalter, 2012; Brownscombe et al., 2014; Danylchuk et al., 2014).

In conjunction with methods to determine mortality, the reflex action

tol Bay commercial fishery. Reg. Inf. Rep. 4K94-40, 21 p. Alaska Dep. Fish Game, Kodiak, AK. 
mortality predictor (RAMP) approach has been developed (Davis and Ottmar, 2006). This method relates impairment in reflex actions to the probability of mortality. This relationship is established by first selecting reflexes that give a consistent, instantaneous, and involuntary response to a stimulus. After enduring the set of stressors associated with fishing and discarding (either directly during fishing operations or through simulation in a laboratory), the animals can be evaluated by determining whether each of these reflexes is present. To relate the levels of reflex impairment (i.e., the total number of missing reflexes) to the probability of mortality, survival must be determined by using one of the methods described previously (captive holding, tagging, etc.). A "RAMP relationship" is subsequently created by determining the number of animals, for each level of impairment, that die out of those monitored for mortality. Once established, this relationship can be applied to reflex-impairment data collected over the spatial and temporal extent of a fishery, making the mortality rates more representative of the fishery at large.

The efficacy of a RAMP relationship is linked with the reliability of the predicted delayed mortality rates. Therefore, it is essential to consider method-specific biases and limitations. For example, it is important to evaluate the contribution to mortality from tagging for identification (Tegelberg and Magoon, 1971; Wassenberg and Hill, 1993) or telemetry studies, or the contribution that is due to the effect of captivity in research that determines mortality through holding animals (Yochum et al., 2015; Yochum et al., 2017). In addition, methods that do not allow long-term monitoring may underestimate mortality rates caused by chronic, enduring impairment (Wassenberg and Hill, 1993; Bergmann and Moore, 2001).

Mortality rates estimated through captive holding are biased by the unnatural environment or holding conditions (or both) (Yochum et al., 2015; Yochum et al., 2017). Mortality rates could be overestimated because of agonistic interactions or predation among captive animals, suboptimal temperature or water quality, density of animals in holding enclosures, or failure to meet other biological or environmental requirements of the captive animal (Simonson and Hochberg, 1986; Kondzela and Shirley, 1993; Wassenberg and Hill, 1993; Spanoghe and Bourne, 1997; Portz et al., 2006; Weltersbach and Strehlow, 2013). Alternatively, mortality rates could be underestimated because mortality resulting from an animal's inability to obtain food or avoid predation is not incorporated in such studies (Durkin et al., 1984; Uhlmann et al., 2009; Benoît et al., 2010; Urban, 2015). Similarly, the effect of displacement from suitable habitat and the impact from the return to water after capture and handling onboard are not often considered.

Despite limitations of captive holding, RAMP relationships have commonly been created by using onboard holding tanks or laboratory-based holding facilities (Davis, 2007; Stoner et al., 2008; Humborstad et al., 2009; Barkley and Cadrin, 2012; Stoner, 2012; Hammond et al., 2013; Rose et al., 2013; Depestele et al. ${ }^{2}$; McArley and Herbert, 2014; Humborstad et al., 2016). Preference for this approach is largely due to advantages over alternative methods, which include providing scientists with control and allowing them to differentiate causes of mortality, observing degradation in health and changes in behavior, and knowing the time of death (Davis and Ryer ${ }^{3}$ ). Because short-term laboratory holding is frequently used to estimate delayed discard mortality rates, we conducted a field validation study to assess the limitations of this approach. This was done by comparing results from 2 RAMP studies that evaluated delayed mortality, one through tag-returns and one by using laboratory holding. The former study and comparison are described here, and the latter was reported by Yochum et al. (2017). Tagging was selected for the comparison because it allows an evaluation of long-term mortality rates and allows animals to experience more natural conditions after release.

The Oregon (U.S.A.) commercial and recreational Dungeness crab (Cancer magister) fisheries were selected for this study because of their high level of discard, and because Oregon fishermen have experience with tagging studies for these crab, which yielded high tag-return rates (Jow, 1965; Snow and Wagner ${ }^{4}$; Demory $^{5}$; Hildenbrand et al. ${ }^{6}$ ). Additional factors that make Dungeness crab a good candidate for comparing discard mortality in situ and in the laboratory include evidence that they 1) are agonistic and cannibalistic (Jacoby, 1983; Fernández, 1999; Barber and Cobb, 2007), 2) are often preyed upon by seabirds and California sea lions (Zalophus californianus) upon their return to the water, and 3) like many crustaceans, can be difficult to maintain in captivity owing to stress, disease, and sensitivity to temperature and water quality (Burton, 2001; Barrento et al., 2008).

In Oregon, only male Dungeness crab at or above 159 $\mathrm{mm}$ (6.25 in) carapace width (measuring the straight line distance across the carapace, shell edge to shell

\footnotetext{
2 Depestele, J., E. Buyvoets, P. Calebout, M. Desender, J Goossens, E. Lagast, D. Vuylsteke, and C. Vanden Berghe. 2014. Calibration tests for identifying reflex action mortality predictor reflexes for sole (Solea solea) and plaice (Pleuronectes platessa): preliminary results. ILVO-commun. Rep. 158, 30 p. [Available from website.]

${ }^{3}$ Davis, M. W., and C. H. Ryer. 2003. Understanding fish bycatch discard and escapee mortality. AFSC Q. Rep. 2003, Jan-Mar, 9 p. Alaska Fisheries Science Center, Seattle, WA. [Available from website.]

${ }^{4}$ Snow, C. D., and E. J. Wagner. 1965. Tagging of Dungeness crabs with spaghetti and dart tags. Fish Comm. Oregon, Res. Briefs 11:5-13.

${ }^{5}$ Demory, D. 1971. Crab movement off Port Orford, Oregon. Shellfish Invest. Inf. Rep. 70-7. Res. Div., Fish Comm. Oregon, Salem, OR.

${ }^{6}$ Hildenbrand, K., A. Gladics, and B. Eder. 2011. Crab tagging study: adult male Dungeness crab (Metacarcinus magister) movements near Reedsport, Oregon from a fisheries collaborative mark-recapture study, 21 p. Oregon Wave Energy Trust, Portland, OR.
} 


\section{Table 1}

Reflexes used to assess vitality of Dungeness crab (Cancer magister) when applying the reflex action mortality predictor approach for predicting discard mortality, as detailed in Yochum et al. (2017), along with the method for assessment and metrics for determining whether a given reflex is present (a state that includes weak responses) or absent. Reflexes were assessed in the order (1-6) shown.

\begin{tabular}{|c|c|c|c|c|}
\hline Order & Reflex & Method & Present & Absent \\
\hline 1 & Eye retraction & $\begin{array}{l}\text { A probe is used to lightly tap } \\
\text { the top of an eye }\end{array}$ & $\begin{array}{l}\text { Crab retracts the eye } \\
\text { downward }\end{array}$ & $\begin{array}{l}\text { Crab does not react, leaving } \\
\text { the eye in place }\end{array}$ \\
\hline 2 & Mouth defense & $\begin{array}{l}\text { A probe is used to attempt } \\
\text { to pull the } 3^{\text {rd }} \text { maxillipeds } \\
\text { forward }\end{array}$ & $\begin{array}{l}\text { Crab defends its mouthparts } \\
\text { with its chela making it diffi- } \\
\text { cult to access the maxillipeds }\end{array}$ & $\begin{array}{l}\text { Crab allows its maxillipeds to } \\
\text { be manipulated }\end{array}$ \\
\hline 3 & Chela closure & $\begin{array}{l}\text { A probe is placed below the } \\
\text { chela dactyl }\end{array}$ & $\begin{array}{l}\text { Crab reacts by closing the } \\
\text { chela tightly, then opening it } \\
\text { again without manipulation }\end{array}$ & $\begin{array}{l}\text { Crab does not open and close } \\
\text { its chela without manipulation }\end{array}$ \\
\hline 4 & Leg wrap & $\begin{array}{l}\text { A probe is used to pull pereo- } \\
\text { pods } 2-4 \text { to a } 180^{\circ} \text { angle }\end{array}$ & $\begin{array}{l}\text { Crab draws the pereopods } \\
\text { back in (i.e., joints at less } \\
\text { than a } 180^{\circ} \text { angle) }\end{array}$ & $\begin{array}{l}\text { Crab pereopods do not move } \\
\text { without manipulation }\end{array}$ \\
\hline 5 & Leg curl & $\begin{array}{l}\text { Pereopod } 5 \text { is straightened } \\
\text { and pulled downward }\end{array}$ & $\begin{array}{l}\text { Crab pulls up and curls its } \\
\text { pereopod in a controlled } \\
\text { manner }\end{array}$ & $\begin{array}{l}\text { Crab does not move the pereo- } \\
\text { pod without manipulation }\end{array}$ \\
\hline 6 & Abdomen response & $\begin{array}{l}\text { A probe is used to attempt to } \\
\text { pull the top of the abdominal } \\
\text { flap away from the crab's body }\end{array}$ & $\begin{array}{l}\text { Crab exhibits a strong, agi- } \\
\text { tated reaction }\end{array}$ & Crab does not react \\
\hline
\end{tabular}

edge, anterior to the tenth anterolateral spine, not including the spines) may be retained in the commercial fishery, and at or above $146 \mathrm{~mm}$ (5.75 in) in the recreational fishery. Legal-size, soft-shell males are also typically discarded to allow them to harden and fill with flesh after molting ( $\left.\mathrm{PSMFC}^{7} ; \mathrm{ODFW}^{8}\right)$. Through logistic regression modeling, Yochum et al. (2017) estimated delayed discard mortality rates (i.e., the proportion of discarded animals that die within $5 \mathrm{~d}$ of release) for the commercial ocean fishery and recreational bay fisheries (both from a boat and shoreside, i.e., fishing from land rather than a boat, often from a dock or pier). The goal of the tagging study described here was to ascertain whether 1) the laboratory study reported by Yochum et al. (2017) under- or over-estimated the true mortality rates for discarded Dungeness crab, 2) whether there are long-term, chronic effects (attributed to persistent impairment) that lead to delayed mortality that were obfuscated by using short-term monitoring, and 3) whether the impact from the return to water during the process of discarding, a stressor not incorporated in the laboratory study, contributes to mortality. Crab are susceptible to cracked carapaces or fatal injuries (or

${ }^{7}$ PSMFC (Pacific States Marine Fisheries Commission). 1978. Dungeness crab project of the state-federal fisheries management program, 139 p. Pac. States Mar. Fish. Comm., Portland, OR.

8 ODFW (Oregon Department of Fish and Wildlife). 2015. 2015 Oregon sport fishing regulations, 100 p. Oregon Dep. Fish Wildl., Salem, OR. both) when being dropped from a vessel, dock, or pier. Mortality attributed to this impact could therefore explain differences in rates estimated between laboratory and tagging studies and would suggest the importance of including this variable in an estimation of mortality to improve accuracy. Through this research, we also aimed 4) to evaluate tag-return methods for estimating mortality rates based on RAMP scores.

\section{Materials and methods}

\section{Laboratory-holding study}

For the laboratory-holding study (see Yochum et al., 2017 for details), between February 2012 and April 2014 , crab intended for discard were assessed during 22 commercial fishing trips by an accompanying scientist ("ride-alongs") along the Oregon coast. During the same period, an additional 26 recreational fishing trips were completed on a boat in Yaquina Bay (in Oregon), and sampling of the recreational shoreside fishery was completed on 15 occasions at the Port of Newport Public Fishing Pier (Yaquina Bay). A systematic random sample of crab from the commercial fishery, and all "recreationally" caught crab were assessed when they would have been released (i.e., after all handling processes), typically within 10 min of being landed (usually sooner). Crab assessments (completed in less than 1 min per crab) included the following variables: sex, 


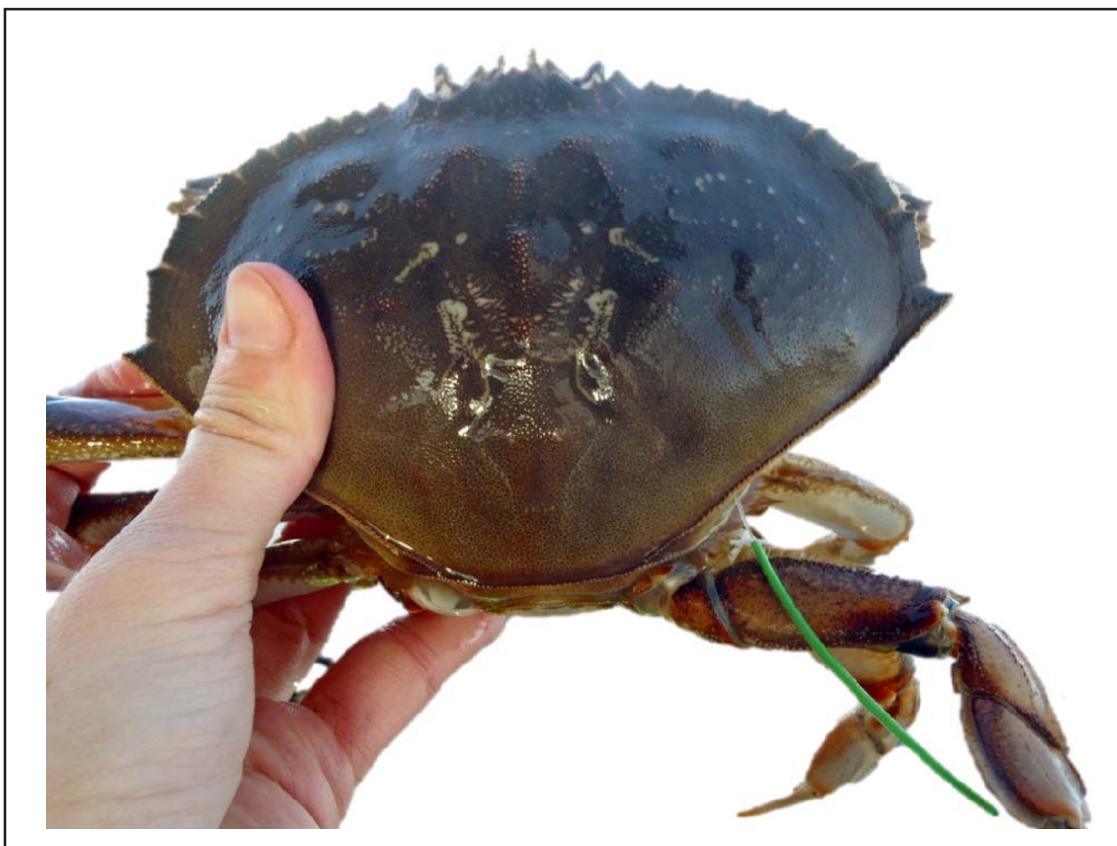

Figure 1

Photograph of a Dungeness crab (Cancer magister) tagged with a double tbar anchor tag (TBA-LEVO) for this study in which Dungeness crabs were tagged and released between October 2012 and April 2014 off the coast of Oregon and in Yaquina Bay, Oregon

shell hardness ("soft": little or no hardening after molting; or "hard": nearly fully hard to near molt), carapace width, presence of new injuries, and amount of time spent out of water before assessment. In addition, each crab was evaluated for presence or absence of the 6 RAMP reflexes established for assessing Dungeness crab vitality (Table 1) and was given a reflex impairment score ("score") equal to the number of absent reflexes (0-6; both weak and strong reflex responses were considered present reflexes). During sampling, $12 \%$ of crab intended for discard $(n=1065)$, representing all impairment scores, were transported to a laboratory for holding to determine mortality rates. Owing to an observed captivity effect for crab of all scores (including score-0 crab), a crab was considered a "mortality" only if it died within the first $5 \mathrm{~d}$ of holding.

\section{Tag-return study}

During the aforementioned sampling trips, beginning in October 2012, we aimed to tag and release all crab not intended for laboratory holding that were also not too small or soft to tag. Crab were tagged with a lime green double 't-bar' anchor tag (TBA-LEVO, Hallprint Fish Tags, ${ }^{9}$ Hindmarsh Valley, Australia; Fig. 1), the same tag type that was used for identification purposes

\footnotetext{
${ }^{9}$ Mention of trade names or commercial companies is for identification purposes only and does not imply endorsement by the National Marine Fisheries Service, NOAA.
}

in the laboratory holding study. Details of tag selection and tagging procedure are provided in Yochum (2016). Tagged crab were released at location of capture, in a manner that attempted to mimic the discard process of a fisherman. Care was taken to randomize and balance the number of crab that were tagged and released vs. returned to the laboratory, over different combinations of score, sex, and shell hardness (Table 2). The same data obtained for held crab were collected for those tagged and released.

An extensive outreach campaign began before the commencement of the tag-return study and was a focal part of the project throughout its duration. To encourage the participation of fishermen (Pollock et al., 2001), for each tag returned (either the physical tag or a picture of the tag was required) fishermen were given $\$ 20$, a hat or a shirt, and an entry ticket for 2 cash-prize raffles that took place in October 2013 and August 2014. Outreach efforts to make fishermen aware of the rewards and project included the following: frequently talking with fishermen (captains and crew) at the docks (and elsewhere) and inquiring if they had tags to return, regularly posting flyers at local docks and in fishing and marine supply stores, and taking additional measures detailed in Yochum (2016). Oregon Sea Grant provided the location where fishermen could return tags and collect rewards in person. We hoped that this arrangement would encourage tag returns given that this organization and location are well known and frequented by fishermen, and because 
Table 2

Total number of Dungeness crab (Cancer magister) that were tagged and released between October 2012 and April 2014 and whose tags were returned, by fishery (commercial ocean off Oregon and recreational in Yaquina Bay, Oregon, by boat and shoreside). Totals are given by sex and shell hardness (combined), and reflex impairment score, which is equal to the number of absent reflexes (out of 6 reflexes assessed).

\begin{tabular}{|c|c|c|c|c|c|c|c|c|c|}
\hline & & \multicolumn{7}{|c|}{ Reflex impairment score } & \multirow[b]{2}{*}{ Total } \\
\hline & & 0 & 1 & 2 & 3 & 4 & 5 & 6 & \\
\hline \multicolumn{10}{|l|}{ Commercial } \\
\hline \multirow[t]{2}{*}{ Total } & Tagged & 2432 & 334 & 85 & 20 & 5 & 2 & 6 & 2884 \\
\hline & Returned & 242 & 32 & 4 & 0 & 0 & 0 & 0 & 278 \\
\hline \multirow[t]{2}{*}{ Female hard-shell } & Tagged & 1429 & 226 & 70 & 20 & 5 & 2 & 6 & 1758 \\
\hline & Returned & 86 & 12 & 3 & 0 & 0 & 0 & 0 & 101 \\
\hline \multirow[t]{2}{*}{ Female soft-shell } & Tagged & 37 & 5 & 1 & - & - & - & - & 43 \\
\hline & Returned & 1 & 0 & 0 & - & - & - & - & 1 \\
\hline \multirow[t]{2}{*}{ Male hard-shell } & Tagged & 871 & 97 & 12 & - & - & - & - & 980 \\
\hline & Returned & 148 & 20 & 1 & - & - & - & - & 169 \\
\hline \multirow[t]{2}{*}{ Male soft-shell } & Tagged & 95 & 6 & 2 & - & - & - & - & 103 \\
\hline & Returned & 7 & 0 & 0 & - & - & - & - & 7 \\
\hline \multicolumn{10}{|l|}{ Recreational-boat } \\
\hline \multirow[t]{2}{*}{ Total } & Tagged & 831 & 57 & 19 & 2 & 1 & 0 & 1 & 911 \\
\hline & Returned & 108 & 11 & 2 & 1 & 0 & 0 & 0 & 122 \\
\hline \multirow[t]{2}{*}{ Female hard-shell } & Tagged & 114 & 9 & - & - & - & - & 1 & 124 \\
\hline & Returned & 6 & 1 & - & - & - & - & 0 & 7 \\
\hline \multirow[t]{2}{*}{ Female soft-shell } & Tagged & 35 & 2 & 1 & - & - & - & - & 38 \\
\hline & Returned & 2 & 0 & 0 & - & - & - & - & 2 \\
\hline \multirow[t]{2}{*}{ Male hard-shell } & Tagged & 586 & 38 & 17 & 1 & 1 & - & - & 643 \\
\hline & Returned & 87 & 7 & 1 & 1 & 0 & - & - & 96 \\
\hline \multirow[t]{2}{*}{ Male soft-shell } & Tagged & 96 & 8 & 1 & 1 & - & - & - & 106 \\
\hline & Returned & 13 & 3 & 1 & 0 & - & - & - & 17 \\
\hline \multicolumn{10}{|l|}{ Recreational-shoreside } \\
\hline \multirow[t]{2}{*}{ Total } & Tagged & 266 & 22 & 7 & 3 & 0 & 0 & 0 & 298 \\
\hline & Returned & 29 & 1 & 0 & 0 & 0 & 0 & 0 & 30 \\
\hline \multirow[t]{2}{*}{ Female hard-shell } & Tagged & 46 & - & 1 & 1 & - & - & - & 48 \\
\hline & Returned & 4 & - & 0 & 0 & - & - & - & 4 \\
\hline \multirow[t]{2}{*}{ Female soft-shell } & Tagged & 14 & - & - & - & - & - & - & 14 \\
\hline & Returned & 0 & - & - & - & - & - & - & 0 \\
\hline \multirow[t]{2}{*}{ Male hard-shell } & Tagged & 184 & 20 & 4 & 1 & - & - & - & 209 \\
\hline & Returned & 23 & 1 & 0 & 0 & - & - & - & 24 \\
\hline \multirow[t]{2}{*}{ Male soft-shell } & Tagged & 22 & 2 & 2 & 1 & - & - & - & 27 \\
\hline & Returned & 2 & 0 & 0 & 0 & - & - & - & 2 \\
\hline \multirow[t]{2}{*}{ Total } & Tagged & 3529 & 413 & 111 & 25 & 6 & 2 & 7 & 4093 \\
\hline & Returned & 379 & 44 & 6 & 1 & 0 & 0 & 0 & 430 \\
\hline
\end{tabular}

this was the place where fishermen returned tags for a previous Dungeness crab tagging study. We attempted to make the tag return process simple by providing multiple ways to exchange the tag for a reward, by requiring minimal paperwork, by allowing fishermen to be instantly rewarded with cash, and by distributing tag-return packets that included tag-return forms, a pen, tape to attach the tag to the form, information on the project, and where to return tags, all inside a waterproof envelope.

\section{Relative short-term survival}

We compared relative short-term (5-d) survival data from the Yochum et al. (2017) laboratory study with data from the tag-return study described here to determine whether delayed mortality rates for discarded Dungeness crab were under- or over-estimated when using laboratory-based RAMP methods. We evaluated relative survival rates between score-0 crab (i.e., no reflex responses missing) and those with scores greater than 0, using an approach described by Hueter et al. (2006). This analysis estimates relative survival between 2 conditions of animals (e.g., good vs. poor) and is done with the assumption that there is a disproportionate survival between the 2 conditions during a short-term "recovery period," and that subsequent survival rates are assumed to be equal for both conditions. The "recovery period" was set at $5 \mathrm{~d}$ because the laboratory study considered mortalities only with- 
in that time frame because of a captivity effect. For the analysis, "condition 1" was assigned to crab with a reflex impairment score equal to 0 . Owing to small sample sizes, scores 1-6 were combined and assigned as "condition 2." Sample size was reduced because of limited numbers of crab with scores greater than 0 for these fisheries and because the comparison had to be done by fishery, sex, and shell hardness given that the laboratory study determined different mortality rates for these variables.

Relative survival rates between conditions 1 (score 0 ) and 2 (score greater than 0 ) after the "recovery period" (i.e., $5 \mathrm{~d}$ in holding for the laboratory study, and $5 \mathrm{~d}$ at large for the tag-return study) were estimated for both studies and compared. This was done with all data combined for the laboratory study, and by release event (i.e., sampling trip) for the tag study to control for the influence on return rate of days-at-large, natural and fishing-induced mortality, and temporal variability in catchability, fishing effort, tag loss, and reporting rate.

$$
\widehat{R}=\frac{C_{2} / C_{1}}{T_{2} / T_{1}}
$$

where $C_{\mathrm{i}}=$ Number of 'surviving' crab after the recovery period (tag study: recaptured tags; laboratory study: surviving crab) for the $i$ th condition

$T_{\mathrm{i}}=$ Total number of experimental crab (tag study: tagged; laboratory study: held) for the $i$ th condition.

Two-sided confidence intervals (CIs) for the survival rates were calculated to compare the 2 studies. They were calculated as (Hueter et al., 2006):

$$
\left(\widehat{R} e^{-Z_{1-\alpha / 2} \sqrt{v}}, \widehat{R} e^{Z_{1-\alpha / 2} \sqrt{v}}\right)
$$

where $Z_{1-\alpha / 2}$ is the $100(1-\alpha / 2)$ th percentile of the standard normal distribution and

$$
v=\frac{T_{1}-C_{1}}{T_{1} C_{1}}+\frac{T_{2}-C_{2}}{T_{2} C_{2}} .
$$

\section{Relative long-term survival}

If there was a more chronic, sublethal effect from the capture, handling, and discard process (e.g., nonlethal physiological impact or change in behavior), a difference in survival rates between conditions could continue beyond a short recovery period (here, $5 \mathrm{~d}$ ). This difference in survival would indicate that laboratory holding under-estimates mortality by evaluating only over the short-term. To evaluate the potential change in relative survival, by condition over time, we used logistic regression in $\mathrm{R}$ software, vers. 3.1.1 ( $\mathrm{R}$ Core Team, 2014) to model the probability that a recaptured tag was from a condition 2 (score greater than 0 ) crab, including a variable for days-at-large, and 3 indicators of sex and shell hardness. This analysis allowed us to determine whether the odds of return between the 2 conditions change over time. A nonzero time-dependent slope coefficient indicates different long-term survival between conditions. The intercept would be 0 if the same number of tagged crabs were released in the 2 conditions and they suffered the same rate of shortterm mortality after $5 \mathrm{~d}$ at large $(t=0)$. If the 2 conditions had the same short-term survival, a nonzero intercept would reflect the ratio of the number of tagged animals in the 2 conditions at $t=0$. We compared crab within a release event with the assumption that relative natural mortality, catchability, and reporting probability are the same for a given condition and release event.

\section{Evaluating the return to water}

In addition to the laboratory holding and tag-return studies, 2 experiments were conducted, one in November 2013 and a second in April 2014, to evaluate the contribution to discard mortality by dropping crab into water. This is a potential cause of different mortality rates between the tag and laboratory studies, and a possible source of error in laboratory-determined mortality rates. For these drop studies, score-0 crab were collected by using recreational fishing gear, tagged, and were held for 2 weeks before experimentation. Then, for each drop height of each experiment, $20 \mathrm{crab}$ at a time were taken out of holding and, for transport to the drop location, were placed in a large ice chest filled with wet burlap (to provide barriers among the crab). For the second study conducted in April 2014 only, the ice chest used for transport was filled with sea water in addition to the burlap so that the crab were in water until they were dropped. At the drop location (approximately $200 \mathrm{~m}$ away), 3 crab at a time were taken out of the ice chest, lifted to one of 3 drop heights, and released (dropped) one-by-one into a tank of sea water. Drop heights for both experiments were $8 \mathrm{~m}$ ("high") and $3 \mathrm{~m}$ ("medium"). Crab were also dropped from $1 \mathrm{~m}$ ("low") for the first study and from $6 \mathrm{~m}$ ('high') for the second study. The drop distances reflected an attempt to mimic the distance a crab would typically fall during discard from recreational and commercial vessels ("low" and "medium" distances, respectively). The "high" distances were approximations of the maximum distance that a crab would be thrown from a pier or dock during shoreside recreational fishing at low tide $(8 \mathrm{~m})$, and a height similar to the distance from the rail of the Newport Pier to the water at mean lower low water $(6 \mathrm{~m})$. For the first experiment, we attempted to drop half of the crab from each height such that they would land dorsally and the other half ventrally. For the second experiment, the side on which the crab landed was not forced (merely noted). After 3 crab were dropped, they were removed from the sea water tank and placed in an ice chest filled with sea water and burlap. For each height treatment, once all 20 crab were dropped, they were taken back to the holding tanks and placed in individual compartments, and mortality was determined after $5 \mathrm{~d}$. 
Table 3

Information on Dungeness crab (Cancer magister) that were tagged and released between October 2012 and April 2014 and differences between crab that were and were not recaptured and their tags returned (all release events combined) for the commercial ocean fishery off Oregon and recreational fisheries in Yaquina Bay, Oregon, by boat and shoreside. Information includes the number of days at large (time between release and recapture of crab for which tags were returned and between release and end of the study for crab for which tags were not returned), carapace width, reflex impairment score (score), water depth at the location the tagged crab was released, and the number of days from the opening of the fishery in which the tagged crab was released (commercial fishery only).

\begin{tabular}{lccccc}
\hline & \multicolumn{2}{c}{ Tag returned } & & \multicolumn{2}{c}{ Tag not returned } \\
\cline { 2 - 3 } \cline { 5 - 6 } & Mean & Range & & Mean & Range \\
\hline Commercial & & & & \\
Days at large & 107 & $2-468$ & & 499 & $209-590$ \\
Carapace width (mm) & 155 & $138-171$ & & 154 & $52-193$ \\
Score & 0.14 & $0-2$ & & 0.25 & $0-6$ \\
Depth at release (m) & 49 & $5-150$ & & 51 & $5-150$ \\
Days from opening of fishery & 66 & $0-198$ & & 83 & $0-198$ \\
& & & & \\
Recreational-boat & 78 & $0-449$ & & 448 & $136-674$ \\
Days at large & 137 & $104-183$ & & 127 & $82-167$ \\
Carapace width (mm) & 0.15 & $0-3$ & & 0.12 & $0-6$ \\
Score & 14 & $4-28$ & & 14 & $4-28$ \\
Depth at release (m) & & & & \\
Recreational-shoreside & 79 & $0-163$ & & 268 & $146-672$ \\
Days at large & 124 & $106-154$ & & 119 & $86-159$ \\
Carapace width (mm) & 0.03 & $0-1$ & & 0.16 & $0-3$ \\
Score & & & &
\end{tabular}

Logistic regression modeling in $\mathrm{R}$ software was used to determine whether there is a relationship between drop height and the probability that a crab died within $5 \mathrm{~d}$ of holding, and whether any other variables influenced the likelihood of survival, including 1) the November 2013 vs. April 2014 experiment (the difference between the 2 being whether or not the crab was kept in water before being dropped), 2) the side on which the crab landed (dorsal, ventral, or side), 3) carapace width (in millimeters; continuous), 4) sex, 5) shell hardness (soft or hard), and 6) whether or not the carapace cracked as a result of the drop. Model coefficients were estimated by using maximum likelihood (Ramsey and Schafer, 2002) based on the fate (mortality or survival) of individual crab that were held after the drop experiments. Akaike information criteria were used to determine the most parsimonious model for the data.

\section{Results}

\section{Tag-return study}

A total of 4093 live crab intended for discard were tagged and released, and 430 tags were returned by 15 August 2014 (11\%; Table 2). Tags were returned by
207 different fishermen, ranging from 1 to 60 tags/fisherman (average: 2 tags/fisherman; mode: 1 tag/fisherman). When the date of recapture was known, 3 tagged crab were recaptured the same day on which they were released, 53 within the first week at large (12\% of the returns), 142 within the first $30 \mathrm{~d}$ (33\%), 295 within the first $100 \mathrm{~d}(69 \%)$, and 415 within a year (97\%). The longest time between release and return was 468 d (Table 3). On average, returned tags were at large for $98 \mathrm{~d}$. With respect to movement, the Euclidean distance from release to recapture locations ranged from 0 to $150 \mathrm{~km}$ (Fig. 2), and there was no relationship between days-at-large and total distance. Some of the farthest distances $(>100 \mathrm{~km})$ occurred within a week at large, and some of the shortest distances $(<1 \mathrm{~km})$ were detected after a year. The majority $(73 \%)$ of recaptured crab, however, were caught less than $10 \mathrm{~km}$ from the release location (59\% for the commercial fishery; $98 \%$ and $100 \%$ for the recreational by boat and shoreside fisheries, respectively). For the recreational fisheries, $43 \%$ (by boat) and $58 \%$ (shoreside) of recaptures were within $1 \mathrm{~km}$. For the commercial fishery, 93\% of crab were recaptured within $50 \mathrm{~km}$, indicating that the probability of recapture was likely not reduced by animals moving out of the area. There was a pattern that recaptures were closer to shore at the start of the 


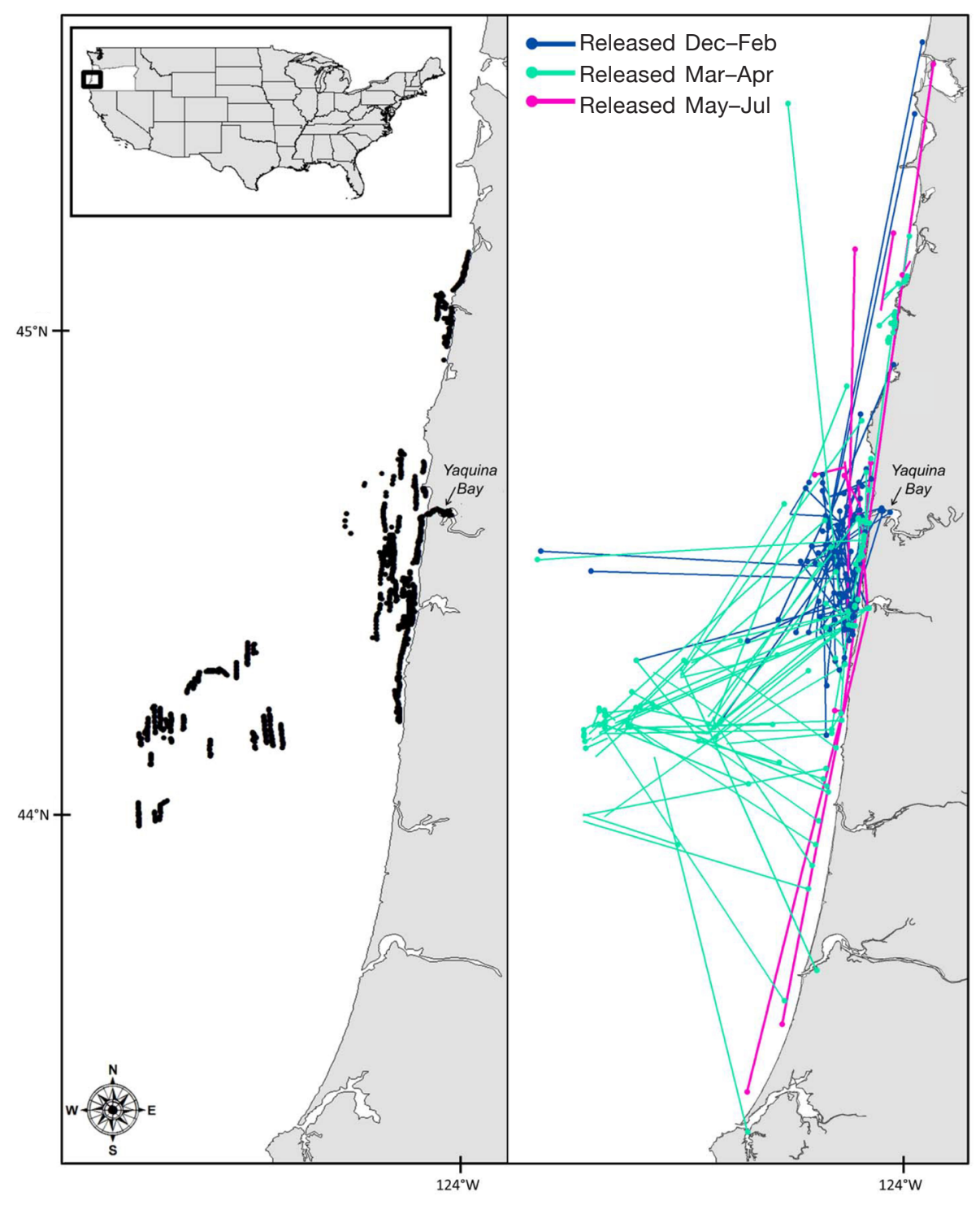

Figure 2

Map showing locations where Dungeness crab (Cancer magister) were tagged and released between October 2012 and April 2014 for the commercial ocean fishery and for recreational fisheries (left panel) and release and recapture locations of crabs released during ride-along commercial ocean fishing trips only (right panel). The dots (right panel) indicate recapture locations and the lines connected to the release location indicate the total Euclidean distance between release and recapture locations.

fishery (December-February; Fig. 2); however, it is difficult to disentangle movement of the crab from that of the fishermen (Demory ${ }^{5}$; Hildenbrand et al. ${ }^{6}$; Barry ${ }^{10}$ ).

For tag return rates, the highest was for male hardshell crab (16\%, 289 of 1832), followed by male softshell crab (11\%, 26 of 236), female hard-shell crab (6\%, 112 of 1930), and female soft-shell crab (3\%, 3 of 95; Table 2; Fig. 3). For score-0 crab only, the proportions

\footnotetext{
${ }^{10}$ Barry, S. 1983. Coastal Dungeness crab project. Washington Dep. Fish., Proj. Compl. Rep. Project No. 1-135-R, 60 p. Washington Dep. Fish., Olympia, WA.
}

of returns did not change from the values listed above, with the exception of returns for male soft-shell crab $(10 \%)$. For all sex and shell hardness combinations, the average score for noninjured crab was lower than that for injured crab (all combined: 0.18 noninjured; 0.49 for injured). With respect to returns by score, the commercial and shoreside fisheries had decreased returns as score increased, whereas there was no clear pattern for the recreational bay fishery from a boat.

Differences were detected between tagged crab that were and were not recaptured (Table 3). Returned tags were from crab that had lower scores, on average, than 

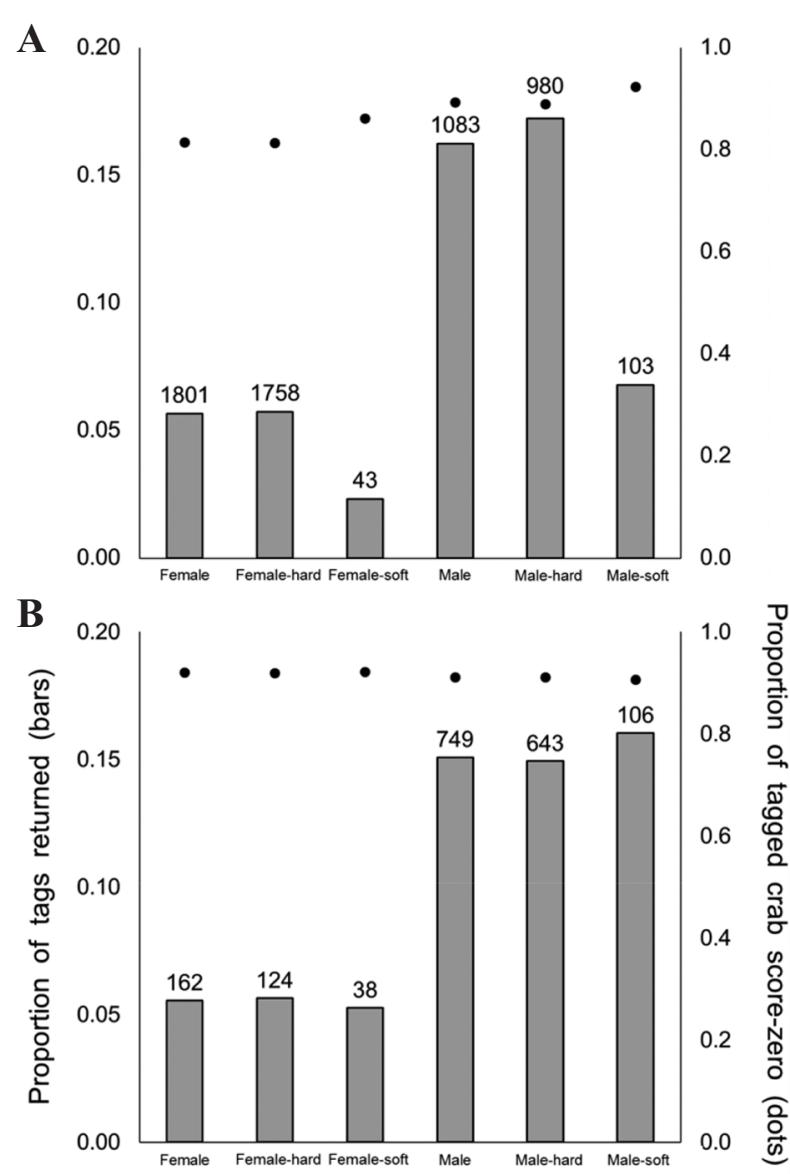

C

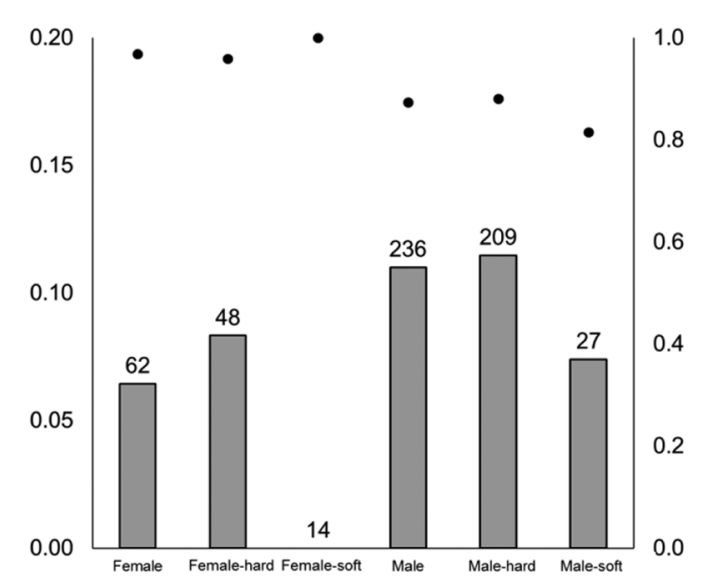

Figure 3

The proportion of Dungeness crab (Cancer magister) tagged and released between October 2012 and April 2014 whose tags were returned (vertical bars) and the proportion of tagged crab that were assigned a reflex impairment score of 0 (i.e., no missing reflexes; dots) by fishery for (A) the commercial ocean fishery off Oregon and recreational fisheries in Yaquina Bay, Oregon, (B) the recreational boat fishery, and (C) the shoreside recreational fishery. The reflex impairment score was further differentiated by sex and shell hardness. The numbers above the vertical bars indicate the total number of crabs for each category that were tagged and released. crab whose tags were not returned. Also, nonreturned tags were on smaller crab, on average, than those returned, and the minimum size was smaller. There was minimal cross-over among the 3 fisheries (Fig. 2). Of tags released in the commercial fishery, $90 \%$ were recaptured during commercial fishing operations. For those tagged during recreational fishing by boat, $96 \%$ were recaptured by recreational fishing and $3 \%$ by commercial fishing. For those released at the Newport Pier, 96\% were recaptured by recreational fishing and $4 \%$ by another means.

Commercial ocean fishery There were 13 tag and release events for the commercial ocean fishery, and $10 \%$ of tags were returned (278 of 2884; Table 2). Males had higher tag return rates than females (16\% vs. 6\%), and, for both sexes, hard-shell crab had higher return rates than soft-shell (10\% vs. $5 \%$; Fig. 3). For female hard- and soft-shell crab, and male hard- and soft-shell crab, the percentages of tags applied to score-0 crab were $81 \%, 86 \%, 89 \%$, and $92 \%$, respectively. The proportion of tags returned was highest when released at the start of the fishing season (2011-12 season opened on 15 December; 2012-13 season on 31 December; and 2013-14 season on 16 December), and decreased over the following months toward the end of the season (15 August; Fig. 4). This pattern was observed regardless of the composition of tagged crab, by sex and shell hardness, or the proportion of tagged crab that were score-0. Similarly, an evaluation of the cumulative proportion of tags returned over time, by release event, revealed higher overall return rates when tags were released closer to the beginning of the season, and that days-at-large influenced overall returns less than month of release (Fig. 5).

Recreational fisheries For the recreational bay fisheries by boat and shoreside, there were 19 and 8 release events, respectively (Table 2), and, $13 \%$ (122 of 911) and 10\% (30 of 298) of tags were returned. For tags recovered by recreational fishing gear, 66\% were caught in pots and $25 \%$ in rings. For the "by boat" fishery, $3 \%$ of injured crab were returned compared with $14 \%$ of noninjured crab (all other variables combined). Also, although return rates for this fishery were similar for crab with hard- and soft-shells (15\% to $16 \%$ for males; $6 \%$ and $5 \%$ for females), overall return rates for females were lower than for males (Fig. 3). Patterns in tag-return data suggest that the probability of return was not clearly linked with reflex impairment score or shell hardness (Fig. 3), and was lower in general than the other fisheries. Finally, unlike the commercial fishery, there were no clear temporal patterns in returns.

For the "shoreside" fishery, tag-return rates were higher for males than for females (11\% vs. 6\%; Table 2), and, within sex, for hard-shell crab than for soft-shell crab (8\% vs. $0 \%$ for females; $11 \%$ vs. $7 \%$ for males), regardless of the proportion that were score-0 (Fig. 3). Also for this fishery, there were 


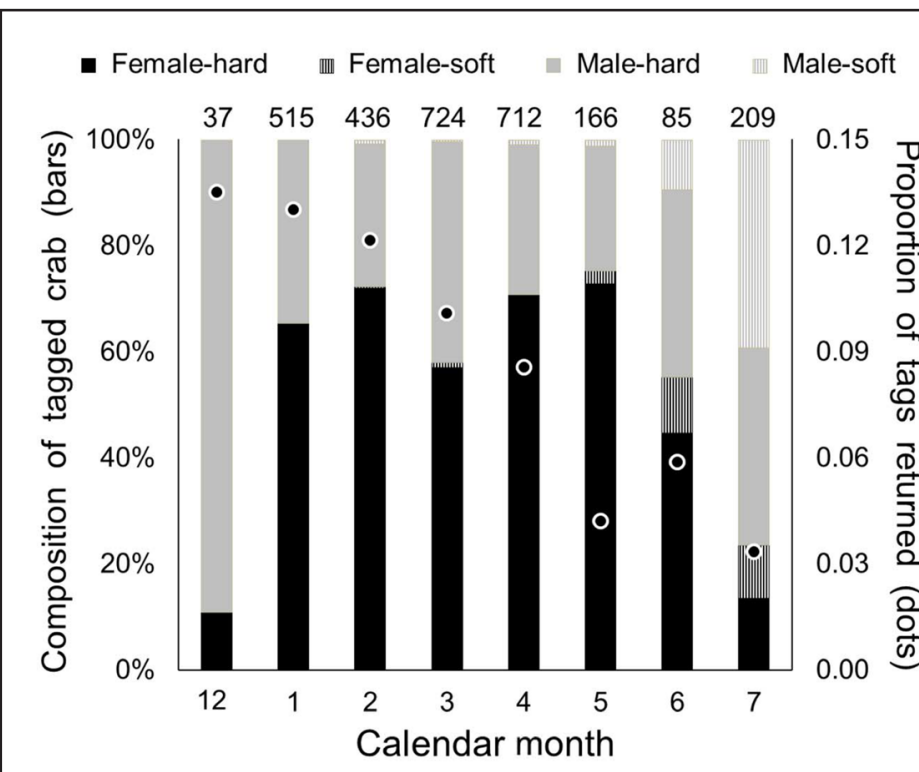

Figure 4

Composition of Dungeness crabs (Cancer magister) that were tagged and released during commercial fishing trips off Oregon between October 2012 and April 2014 and for which tags were returned, by combination of sex and shell hardness (bars), and proportion of crabs for which tags were returned (dots) by the numeric calendar month in which the tagged crabs were released (from December to July). The numbers above the bars indicate the total number of tags released by month.

some cases and, in others, that condition -1 crab had higher survival. For all fisheries, the relative survival ratio for hard-shell males was either equal to or very close to 1 , indicating no differences in survival between conditions. For females, $95 \%$ CIs of the ratios overlapped with 1 for the recreational fisheries, but the ratio for the commercial ocean fishery indicated higher survival for condition-1 crab. For both the commercial ocean and recreational bay byboat fisheries, the ratios indicated higher survival for condition -1 soft-shell male crab than for condition-2 soft-shell male crab. The $95 \%$ CIs of these ratios, however, included a value of 1 .

\section{Relative long-term survival}

Model results indicated that, for all release events where there were adequate sample sizes to complete the analysis, the intercept and variable coefficients were not significantly different from zero. When back-transformed from the logit scale and plotted, however, the intercepts were consistently at or above 0.5 (i.e., the proportion of tag returns from condition- 2 crab were $50 \%$ or greater, even though there were higher numbers of tags released for condition-1 crab). The estimated slope coefficients for the majority of the release events, although not significant, were negative (i.e., the log-odds of a returned tag being from a condition- 2 crab

higher return rates for noninjured crab than injured (all combined: 11\% noninjured, 3\% injured). This was consistent for both sexes (males $12 \%$ vs. $4 \%$, females $7 \%$ vs. 0\%); however, there were only 25 injured of tagged crab and the average reflex impairment score was higher for injured animals, suggesting that, as with the commercial fishery, the decrease in probability of return for injured crab was likely represented by the reflex impairment score.

\section{Relative short-term survival}

The ratios of short-term survival rates of condition 2 (score greater than 0 ) to condition 1 (score-0) crab were highly variable among release events for the tagreturn study (Fig. 6) but indicated minimal differences in survival between conditions. Some release events indicated that condition-1 crab had higher survival than crab classified as condition 2, and others the opposite. Regardless, for all release events for females and hardshell males, the overlapping CIs indicated no statistical difference between conditions. For soft-shell males, there was only one release event with enough data to calculate a relative survival rate. That event indicated survival was higher for condition-2 crab.

Ratios of relative short-term survival of condition-2 to condition-1 crab in the laboratory holding experiment indicated no difference between conditions in decreased over time). If significant, this would indicate a chronic difference in survival between conditions, namely that probability of a tag return, and therefore survival, for condition-2 crab could decrease over time relative to condition- 1 crab. There were no consistent patterns, however, among release events that would signify an optimal monitoring duration beyond the $5 \mathrm{~d}$ "recovery period." Also, the lack of significance in the estimated model coefficients means there were no detected changes over time in the relative probability of a tag being returned from a condition-1 or -2 crab.

\section{Evaluating the return to water}

For the first drop experiment, 21 crab were dropped from $1 \mathrm{~m}, 22$ from $3 \mathrm{~m}$, and 20 from $8 \mathrm{~m}$. There were only 7 soft-shell males and 6 soft-shell females dropped for all heights combined, and $81 \%, 73 \%$, and $70 \%$, respectively, by drop height were male. By drop height, $0 \%(1 \mathrm{~m}), 5 \%(3 \mathrm{~m})$, and $45 \%(8 \mathrm{~m})$ died within $5 \mathrm{~d}$ of holding. The one crab that died from the 3-m drop was a soft-shell female that had incurred both a broken leg and an autotomized leg from the drop. From $8 \mathrm{~m}, 6$ of the 9 mortalities were male, and 3 were female $(43 \%$ of males died, and $50 \%$ of females). All of the crab that died for this experiment, except one, had a cracked carapace as a result of the drop.

For the second experiment, a total of 18 crab were 


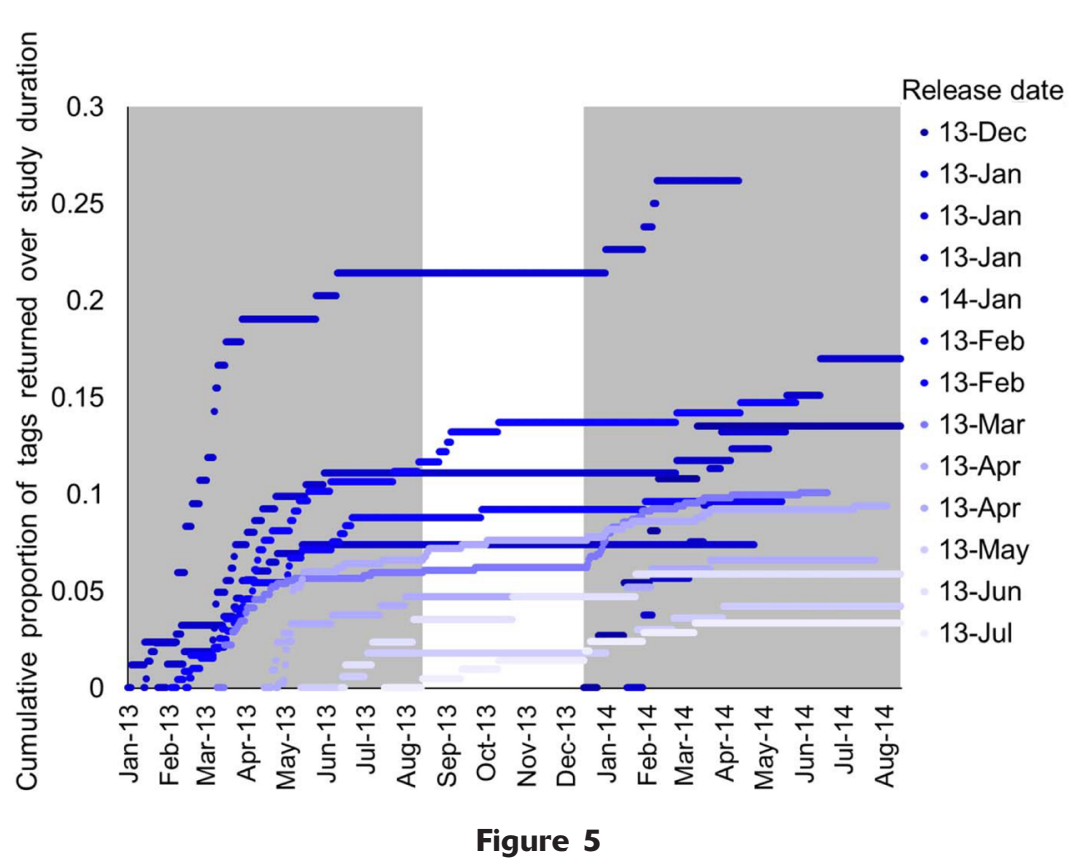

Cumulative proportion of Dungeness crab (Cancer magister) that were tagged and released during commercial fishing trips off Oregon between October 2012 and April 2014 and whose tags were returned over the duration of the study, by release event (year and month released). Darker symbols indicate release events earlier in the fishing season, fading in color as the season advances (from December to July). The gray background indicates when the fishing season was open.

the role of shell hardness in inducing mortality.

\section{Discussion}

\section{Patterns in delayed discard mortality based on tag-returns}

Commercial ocean fishery Probability of tag return for the commercial ocean fishery was influenced by reflex impairment score, sex, shell hardness, carapace width, and time of release in relation to the opening of the fishing season. Males had higher tag-return rates than females and, for both sexes, hardshell crab had higher rates than soft-shell crab. Similar percentages of score- 0 crab were tagged for each category, which suggests that differences in returns were not influenced by discrepancies in composition of tagged crab by score, but rather by differences in survival. The few returns of tagged crab with scores greater than 0 (36) limited an analysis of return trends by individual score. However, decreasing returns as scores increased for females and soft-shell males and lower scores, on average, for returned

dropped from $3 \mathrm{~m}, 18$ from $6 \mathrm{~m}$, and 22 from $8 \mathrm{~m}$. Respectively, $83 \%, 89 \%$, and $82 \%$ were male; and only 1 soft-shell male and 3 soft-shell females were dropped for all heights combined. By drop height, 0\% (3 m), 0\% $(6 \mathrm{~m})$, and $14 \%(8 \mathrm{~m})$, respectively, died within $5 \mathrm{~d}$ of holding. From $8 \mathrm{~m}$, only males died ( 3 of 18 males compared to 0 of 4 females), and all dead crab had major carapace cracks.

Results from logistic regression indicated that mortality from the return to water is primarily influenced by whether or not the carapace cracks as a result of the drop. Whether a carapace cracked was closely linked with drop height and whether or not the crab was in water before being dropped. Both experiments combined, by height, revealed that $0 \%(1 \mathrm{~m}), 0 \%(3 \mathrm{~m})$, $6 \%(6 \mathrm{~m})$, and $33 \%(8 \mathrm{~m})$ of crab had cracked carapaces as a result of the drop, indicating an increased probability of cracking as drop height increases. Considering whether or not the crab was left out of water before it was dropped, for just the $8 \mathrm{~m}$ drop, $55 \%$ of those left out of water (experiment 1) and $14 \%$ of those kept in water (experiment 2) had cracked carapaces. These results suggest that mortality could be linked with whether or not a carapace cracks, which is potentially influenced by both drop height and whether or not a crab is left out of water before being returned to water. Further investigation is needed to determine crab are consistent with the idea that crab with higher reflex impairment scores had higher rates of mortality. Moreover, lower average scores for noninjured crab compared with injured crab supports the assumption that injury is reflected in the score. These tag-return patterns mirror results from the laboratory study in which delayed discard mortality rates were dependent upon level of reflex impairment (increasing mortality with higher scores), sex (higher mortality for females), and shell hardness (soft-shell males had higher mortality than hard-shell males; few soft-shell females were captured requiring soft- and hard-shell females to be combined for the laboratory study).

Patterns in tag-return rates indicated potential bias due to carapace width and month of release. For both sexes, the frequency of returns was higher for crab with larger carapace widths than for smaller tagged crab, possibly indicating that size affected the likelihood of return. This could be due to the fact that fishermen immediately discard crab with carapaces that are clearly smaller than the legal-size requirement without evaluation. In addition, a tag was more likely to be returned if tagged and released closer to the beginning of the season, likely because effort is highest at this time (i.e., there are more vessels on the water and, therefore, more pots pulled) and decreases over the fishing season. 


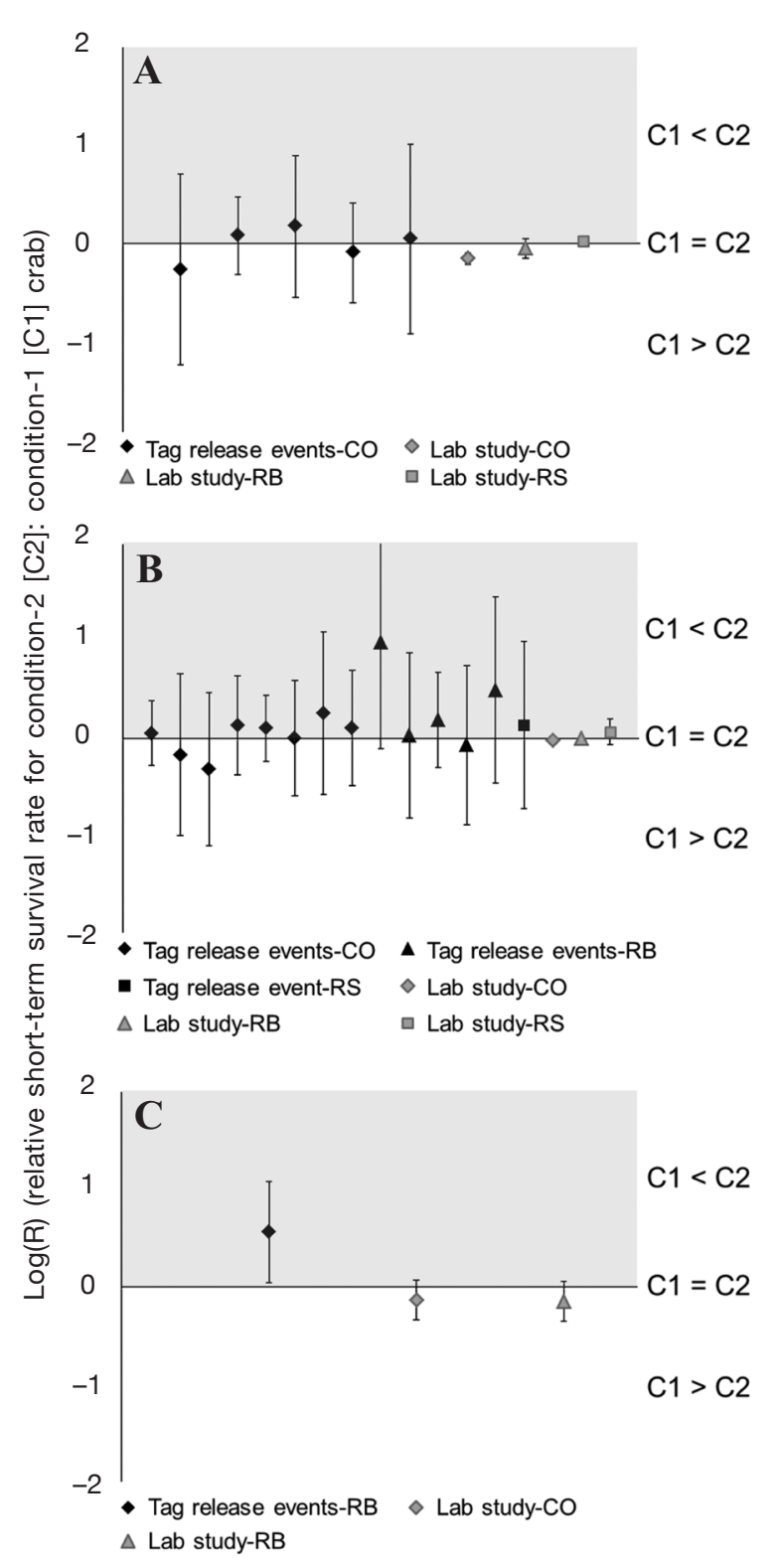

Figure 6

The relative short-term survival rates of Dungeness crabs (Cancer magister) collected off Oregon between February 2012 and April 2014 and classified as condition 2 (C2: reflex impairment score $>0$ ) or as condition 1 (C1: score=0) for tag release events and the laboratory holding study by fishery (commercial ocean fishery $[\mathrm{CO}]$ and recreational fisheries in Yaquina Bay, by boat [RB] and shoreside [RS]). (A) females, (B) hard-shell males, and (C) soft-shell males. Hard- and soft-shell females were combined owing to low numbers of the latter caught and, therefore, held or tagged). Note that the upper confidence limit (2.07) for the first RB tag release event for hard-shell males exceeded the axis rule.
Recreational fisheries Patterns in tag-return data from the recreational bay fishery from a boat are similar to mortality rate patterns from the laboratory-holding study for this fishery in that reflex impairment score and shell hardness were weak predictors, and rates were lower than those of the other fisheries. For the laboratory study, the most important predictor of delayed mortality was whether or not the crab had any missing reflexes (a binary response). Mortality rates for crab were statistically indistinguishable by the level of impairment. However, modeling outcomes for this fishery could have been influenced by the low numbers of crab with missing reflexes and the high proportion of hard-shell males caught, and, therefore, held in captivity, which had a higher survival rate than females and soft-shell crab from the commercial fishery. Also similar to trends in the laboratory study, noninjured crab had a higher return rate than injured crab. However, the significance of the relationship between the probability of tag return and injury was difficult to measure given the small number (35) of injured crab that were tagged and released. As in the commercial fishery, patterns in tag returns suggest that carapace width and sex may also have influenced return rates with this fishery. The frequency of returns was higher for crab with larger carapaces compared with the size frequency of those tagged. Also, overall return rates for females were lower than those for males. Although this result could reflect reduced survival for females that went undetected in the laboratory-holding study, it could also be indicative of a bias caused by fishermen and attributable to the sex of the crab. As they do with small crab, fishermen instinctually discard females without much inspection, while males are measured to determine their legal status. In measuring the crab, fishermen have more opportunities to observe the tag.

Mortality rates were not estimated for the recreational shoreside fishery in the laboratory holding study. However, Yochum et al. (2017) found that rates were likely more similar to those estimated for the commercial ocean fishery than the recreational bay fishery from a boat (Yochum et al., 2017). Tag returns for the recreational bay shoreside fishery, like the commercial sector, indicated that the probability of return is likely influenced by reflex impairment score, sex, shell hardness, and carapace width. This notion is consistent with laboratory findings, which indicated that mortality rates for the commercial ocean fishery could likely be applied to the shoreside fishery. With respect to bias, as with other fisheries, return rates were higher for larger crab. There were no clear temporal patterns; however, sample sizes were small for each release event.

\section{Efficacy of tag-return methods for research on discard mortality}

There are limitations when using tag-return methods to evaluate discard mortality for a low-impact fishery (i.e., one where, for the majority of animals, the stress- 
ors do not impair the reflexes). In analyses, in absence of a control to evaluate score- 0 crab and with low numbers of reflex-impaired animals, crab with scores greater than zero were combined. Therefore, crab with low mortality probabilities (e.g., score-1) were mixed with moribund animals (score-6), which obfuscated a clear comparison of crab with different levels of impairment and prevented the detection of statistical differences in relative short- and long-term survival rates between the laboratory and tagging studies.

These limitations highlight the importance of being able to tag and recapture a sufficient number of animals for each reflex impairment score when executing a tag-return study using the RAMP approach. Hueter et al. (2006), in describing the methods used here to look at relative short-term survival, tagged a minimum of 365 animals per condition. For the commercial ocean fishery, which had the highest number of crab with scores greater than 0 , of the 5594 crab assessed overall, only 202 had reflex impairment scores greater than 1 (129 score-2; 46 score-3; 14 score-4; 5 score-5; and 8 score-6; Yochum et al., 2017). These sample sizes are even smaller when divided into subcategories for sex and shell hardness, and when the lower-impact fisheries are considered. Moreover, the requirement of tagging a sufficient number of soft-shell crab becomes logistically impractical because the highest return rates are linked with release events early in the fishing season, a time when there are few to no soft-shell animals.

The efficacy of applying a tag-return approach for discard mortality research is also linked with the extensive list of factors that determine whether or not a tag will be returned. For this study, these included natural mortality, fishing-induced mortality (both retention and handling-induced mortality if a tagged animal is recaptured and released without the tag being observed), catchability, molt failure attributed to the tag, tag loss, tag-induced mortality, and reporting rate. Each of these factors is a potential source of bias in tag-return rates. In the case of Dungeness crab, natural mortality, for example, differs for crab that are and are not molting (Zhang et al., 2004). In addition, fishinginduced mortality must be considered when evaluating soft-shell crab that, after a period of time, become hard and recruit back into the fishery, or when evaluating sublegal crab that become legal size after molting during the study period. Moreover, different catchabilities could apply to recently molted male crab (Taggart et al., 2004), female crab based on whether or not they are egg-bearing (Swiney et al., 2003), and crab with different reflex impairment scores if a reduction in vitality affects a crab's inclination to eat and therefore enter a pot. Also, for the commercial fishery, there are temporal and spatial patterns in fishing practices (Gotshall, 1978; Barry $^{10}$ ) that could affect tag return rates differently. The majority of effort and landings for the commercial Dungeness crab fishery occurs shortly after the season opens in December and during the first 2 months, after which fishermen often switch to an alternative fishery (Didier, 2002; Goblirsch and Theberge $\left.{ }^{11}\right)$. Because of this temporal trend, crab tagged and released near the beginning of the season (or crab at large during multiple season openings) have a higher chance of being observed than those tagged toward the end of the season when fishing effort is lower. The physical presence of the tag may also affect return rates given its potential to impede molting, to be lost, or contribute to mortality. In addition, tag reporting is potentially dependent on successful and extensive outreach, and the willingness and ability of fishermen to participate (Pollock et al., 2001). Finally, conducting a tag-return study on discarded animals can be challenging because they are less likely to be inspected than retained animals. Furthermore, some fishermen reported that, because female and sublegal-size male crab are not allowed to be retained, they were not sure if they were supposed to remove the tag or leave it in place. However, if sufficient tag returns permit relative analysis by score for a single release event, then many of the aforementioned variables of concern become irrelevant.

\section{Reliability of estimating mortality under captive holding conditions}

To address the goal of the field validation in ascertaining the accuracy of the laboratory-based mortality rates estimated by Yochum et al. (2017) for Dungeness crab, we conclude that, although direct rate comparisons were not possible, similar patterns in mortality- and tag return- rates from the 2 studies lend support to the reliability of the laboratory-generated rates. However, results from the tagging study suggest that laboratorybased mortality rates for discarded females should be evaluated to determine whether there is a discrepancy between hard- and soft-shell crab. In addition, mortality would be underestimated if the laboratory-based commercial rates were applied to a shoreside fishery where the discarded crab fell more than $6 \mathrm{~m}$ (and potentially less). With respect to chronic mortality, for all fisheries, there was no conclusive evidence that suggests mortality rates were underestimated in the laboratory study because of short-term holding.

In general, trade-offs between laboratory holding and tag-return for estimating discard mortality rates depend on the overall objectives of the study, logistic constraints, and the level of impairment caused by the stressor(s) being studied. For our 2 studies, the laboratory-based RAMP approach was superior in its ability to quantify mortality rates and to detect significant differences among several variables. Regardless, the tag-return study identified important influences on mortality and allowed increased collaboration and outreach in the fishing community. In addition, advantages of the tag-return approach over captive holding include the fact that the conditions with the former

\footnotetext{
${ }^{11}$ Goblirsch, G., and S. Theberge. 2008. Traps. Sea Grant Oregon ORESU-G-08-002, 2 p. Oregon State Univ., Corvallis, OR. [Available from website.]
} 
approach more closely mimic actual fishing stressors and a more natural environment after release, and reduce handling (transporting the animals from the fishing vessel to the laboratory and maintaining them in tanks). For the Oregon Dungeness crab fisheries, these approaches, used together, provided a more comprehensive evaluation of what affects survival of discarded crab. In both studies, sample size is highlighted as a critical consideration when applying the RAMP approach to a low-impact fishery.

\section{Acknowledgments}

We are grateful for the ride-along opportunities provided by R. Carel, B. Eder, D. Lemon, and A. Pazar, and for the assistance provided by the crews of the FVs Delma Ann, Maggie, and Timmy Boy. We thank J. Ainsworth, K. Buisman, D. Hall, J. Hoenig, P. Iseri, K. Jacobson, A. Levings, B. Milano, M. Osterhoudt, D. Phillips, M. Vance, and the Oregon Dungeness Crab Commission for their contribution to this research. Funding for this project was provided by the Mamie Markham Research Award and the National Marine Fisheries Service Bycatch Reduction Engineering Program (award NA12NMF4720249).

\section{Literature cited}

Barber, J. S., and J. S. Cobb. 2007. Injury in trapped Dungeness crabs (Cancer magister). ICES J. Mar. Sci.64:464-472. Article

Barkley, A. S., and S. X. Cadrin.

2012. Discard mortality estimation of yellowtail flounder using reflex action mortality predictors. Trans. Am. Fish. Soc. 141:638-644. Article

Barrento, S., A. Marques, S. Pedro, P. Vaz-Pires, and M. L. Nunes.

2008. The trade of live crustaceans in Portugal: space for technological improvements. ICES J. Mar. Sci. 65:551559. Article

Benaka, L. R., L. Sharpe., L. Anderson., K. Brennan, J. E. Budrick, C. Lunsford, E. Meredith, M. S. Mohr, and C. Villafana.

2014. Fisheries release mortality: identifying, prioritizing, and resolving data gaps. NOAA Tech. Memo. NMFS-F/ SPO-142, $55 \mathrm{p}$.

Benoît, H. P., T. Hurlbut, and J. Chassé.

2010. Assessing the factors influencing discard mortality of demersal fishes using a semi-quantitative indicator of survival potential. Fish. Res. 106:436-447. Article

Bergmann, M., and P. G. Moore.

2001. Survival of decapod crustaceans discarded in the Nephrops fishery of the Clyde Sea area, Scotland. ICES J. Mar. Sci. 58:163-171. Article

Bergmann, M., A. C. Taylor, and P. G. Moore.

2001. Physiological stress in decapod crustaceans (Munida rugosa and Liocarcinus depurator) discarded in the Clyde Nephrops fishery. J. Exp. Mar. Biol. Ecol. 259:215-229. Article
Bower, S. D., A. J. Danylchuk, J. W. Brownscombe, J. D. Thiem, and S. J. Cooke.

2016. Evaluating effects of catch-and-release angling on peacock bass (Cichla ocellaris) in a Puerto Rican reservoir: a rapid assessment approach. Fish. Res. 175:95102. Article

Brownscombe, J. W., L. Nowell, E. Samson, A. J. Danylchuk, and S. J. Cooke.

2014. Fishing-related stressors inhibit refuge-seeking behavior in released subadult great barracuda. Trans. Am. Fish. Soc. 143:613-617. Article

Brownscombe, J. W., L. P. Griffin, T. Gagne, C. R. Haak, S. J. Cooke, and A. J. Danylchuk.

2015. Physiological stress and reflex impairment of recreationally angled bonefish in Puerto Rico. Environ. Biol. Fish. 98:2287-2295. Article

Burton, C.

2001. Transport of live crustaceans. Shellfish News 11:18-19.

Campbell, M. D., J. Tolan, R. Strauss, and S. L. Diamond. 2010. Relating angling-dependent fish impairment to immediate release mortality of red snapper (Lutjanus campechanus). Fish. Res. 106:64-70. Article

Danylchuk, A. J., C. D. Suski, J. W. Mandelman, K. J. Murchie, C. R. Haak, A. M. L. Brooks, and S. J. Cooke.

2014. Hooking injury, physiological status and short-term mortality of juvenile lemon sharks (Negaprion bevirostris) following catch-and-release recreational angling. Conserv. Physiol. 2:cot036. Article

Davis, M. W.

2007. Simulated fishing experiments for predicting delayed mortality rates using reflex impairment in restrained fish. ICES J. Mar. Sci. 64:1535-1542. Article

Davis, M. W., and M. L. Ottmar.

2006. Wounding and reflex impairment may be predictors for mortality in discarded or escaped fish. Fish. Res. 82:1-6. Article

Diamond, S. L., and M. D. Campbell.

2009. Linking "sink or swim" indicators to delayed mortality in red snapper by using a condition index. Mar. Coast. Fish. 1:107-120. Article

Didier, A. J., Jr.

2002. The Pacific coast Dungeness crab fishery, 10 p. [Report submitted to the Committee on Commerce, Science, and Transportation of the United States Senate and Committee on Resources of the United States House of Representatives.] Pac. States Mar. Fish. Comm., Gladstone, OR. [Available from website.]

Donaldson, M. R., S. G. Hinch, G. D. Raby, D. A. Patterson, A. P. Farrell, and S. J. Cooke.

2012. Population-specific consequences of fisheries-related stressors on adult sockeye salmon. Physiol. Biochem. Zool. 85:729-739. Article

Durkin, J. T., K. D. Buchanan, and T. H. Blahm.

1984. Dungeness crab leg loss in the Columbia River estuary. Mar. Fish. Rev. 46(1):22-24.

Fernández, M.

1999. Cannibalism in Dungeness crab Cancer magister: effects of predator-prey size ratio, density, and habitat type. Mar. Ecol. Prog. Ser. 182:221-230. Article

Gallagher, A. J., J. E. Serafy, S. J. Cooke, and N. Hammerschlag.

2014. Physiological stress response, reflex impairment, and survival of five sympatric shark species following experimental capture and release. Mar. Ecol. Prog. Ser. 496:207-218. Article 
Gotshall, D. W.

1978. Northern California Dungeness crab, Cancer magister, movements as shown by tagging. Calif. Fish Game 64:234-254.

Hammond, C. F., L. L. Conquest, and C. S. Rose.

2013. Using reflex action mortality predictors (RAMP) to evaluate if trawl gear modifications reduce the unobserved mortality of Tanner crab (Chionoecetes bairdi) and snow crab (C. opilio). ICES J. Mar. Sci. 70:1308-1318. Article

Hochhalter, S. J.

2012. Modeling submergence success of discarded yelloweye rockfish (Sebastes ruberrimus) and quillback rockfish (Sebastes maliger): towards improved estimation of total fishery removals. Fish. Res. 127-128:142-147. Article

Hueter, R. E., C. A. Manire, J. P. Tyminski, J. M. Hoenig, and D. A. Hepworth.

2006. Assessing mortality of released or discarded fish using a logistic model of relative survival derived from tagging data. Trans. Am. Fish. Soc. 135:500-508. Article

Humborstad, O.-B., M. W. Davis, and S. Løkkeborg.

2009. Reflex impairment as a measure of vitality and survival potential of Atlantic cod (Gadus morhua). Fish. Bull. 107:395-402.

Humborstad, O.-B., M. Breen, M. W. Davis, S. Løkkeborg, A. Mangor-Jensen, K. Ø. Midling, and R. E. Olsen.

2016. Survival and recovery of longline- and pot-caught cod (Gadus morhua) for use in capture-based aquaculture (CBA). Fish. Res. 174:103-108. Article

Jacoby, C. A.

1983. Ontogeny of behavior in the crab instars of the Dungeness crab, Cancer magister Dana 1852. Zeitschrift für Tierpsychologie 63:1-16. Article

Jow, T.

1965. California-Oregon cooperative crab tagging study. In $16^{\text {th }}$ and $17^{\text {th }}$ annual reports of the Pacific Marine Fisheries Commission for the years 1963 and 1964, p. 51-52. [Report to the Congress of the United States and the governors and legislatures of Washington, Oregon, California, and Idaho.] Pac. Mar. Fish. Comm., Portland, OR. [Available from website.]

Kennelly, S. J., D. Watkins, and J. R. Craig.

1990. Mortality of discarded spanner crabs Ranina ranina (Linnaeus) in a tangle-net fishery-laboratory and field experiments. J. Exp. Mar. Biol. Ecol. 140:39-48. Article

Kondzela, C. M., and T. C. Shirley.

1993. Survival, feeding, and growth of juvenile Dungeness crabs from southeastern Alaska reared at different temperatures. J. Crustac. Biol. 13:25-35. Article

Kruse, G. H., D. Hicks, and M. C. Murphy.

1994. Handling increases mortality of softshell Dungeness crabs returned to the sea. Alaska Fish. Res. Bull. 1:1-9.

McArley, T. J., and N. A. Herbert.

2014. Mortality, physiological stress and reflex impairment in sub-legal Pagrus auratus exposed to simulated angling. J. Exp. Mar. Biol. Ecol. 461:61-72. Article

Nguyen, V. M., E. G. Martins, D. Robichaud, G. D. Raby, M.

R. Donaldson, A. G. Lotto, W. G. Willmore, D. A. Patterson,

A. P. Farrell, S. G. Hinch, et al.

2014. Disentangling the roles of air exposure, gill net injury, and facilitated recovery on the postcapture and release mortality and behavior of adult migratory sockeye salmon (Oncorhynchus nerka) in freshwater. Physiol. Biochem. Zool. 87:125-135. Article

Parker, S. J., P. S. Rankin, R. W. Hannah, and C. B. Schreck. 2003. Discard mortality of trawl-caught lingcod in rela- tion to tow duration and time on deck. North Am. J. Fish. Manage. 23:530-542. Article

Pepperell, J. G., and T. L. O. Davis.

1999. Post-release behaviour of black marlin, Makaira indica, caught off the Great Barrier Reef with sportfishing gear. Mar. Biol. 135:369-380. Article

Pollock, K. H., J. M. Hoenig, W. S. Hearn, and B. Calingaert. 2001. Tag reporting rate estimation: 1 . an evaluation of the high-reward tagging method. North Am. J. Fish. Manag. 21:521-532. Article

Portz, D. E., C. M. Woodley, C.M., and J. J. Cech Jr.

2006. Stress-associated impacts of short-term holding on fishes. Rev. Fish Biol. Fish. 16:125-170. Article

$\mathrm{R}$ Core Team.

2014. R: a language and environment for statistical computing. R Foundation for Statistical Computing, Vienna, Austria [Available from website, accessed January 2015.]

Raby, G. D., M. R. Donaldson, S. G. Hinch, D. A. Patterson, A. G. Lotto, D. Robichaud, K. K. English, W. G. Willmore, A. P. Farrell, M. W. Davis, et al.

2012. Validation of reflex indicators for measuring vitality and predicting the delayed mortality of wild coho salmon bycatch released from fishing gears. J. Appl. Ecol. 49:90-98. Article

Ramsey, F. L., and D. W. Schafer.

2002. The statistical sleuth: a course in methods of data analysis, $2^{\text {nd }}$ ed., 742 p. Duxbury Press, Pacific Grove, CA.

Rose, C. S., C. F. Hammond, A. W. Stoner, J. E. Munk, and J. R. Gauvin.

2013. Quantification and reduction of unobserved mortality rates for snow, southern Tanner, and red king crabs (Chionoecetes opilio, C. bairdi, and Paralithodes camtschaticus) after encounters with trawls on the seafloor. Fish. Bull. 111:42-53. Article

Simonson, J. L., and R. J. Hochberg.

1986. Effects of air exposure and claw breaks on survival of stone crabs Menippe mercenaria. Trans. Am. Fish. Soc. 115:471-477. Article

Spanoghe, P. T., and P. K. Bourne.

1997. Relative influence of environmental factors and processing techniques on Panulirus cygnus morbidity and mortality during simulated live shipments. Mar. Freshw. Res. 48:839-844. Article

Stoner, A. W.

2012. Evaluating vitality and predicting mortality in spot prawn, Pandalus platyceros, using reflex behaviors. Fish. Res. 119-120:108-114. Article

Stoner, A. W., C. S. Rose, J. E. Munk, C. F. Hammond, and M. W. Davis.

2008. An assessment of discard mortality for two Alaskan crab species, Tanner crab (Chionoecetes bairdi) and snow crab (C. opilio), based on reflex impairment. Fish. Bull. 106:337-347.

Swiney, K. M., T. C. Shirley, S. J. Taggart, and C. E. O'Clair. 2003. Dungeness crab, Cancer magister, do not extrude eggs annually in Southeastern Alaska: an in situ study. J. Crustac. Biol. 23:280-288. Article

Taggart, S. J., C. E. O'Clai., T. C. Shirley, and J. Mondragon. 2004. Estimating Dungeness crab (Cancer magister) abundance: crab pots and dive transects compared. Fish. Bull. 102:488-497.

Tegelberg, H. C., and D. Magoon.

1971. Handling mortality on softshell Dungeness crabs. Proc. Natl. Shellfish. Assoc. 61:13. [Abstract.] 
Trumble, R. J., S. M. Kaimmer, and G. H. Williams. 2000. Estimation of discard mortality rates for Pacific halibut bycatch in groundfish longline fisheries. North Am. J. Fish. Manage. 20:931-939.

Uhlmann, S.S., M. K. Broadhurst, B. D. Paterson, D. G. Mayer, P. Butcher, and C. P. Brand.

2009. Mortality and blood loss by blue swimmer crabs (Portunus pelagicus) after simulated capture and discarding from gillnets. ICES J. Mar. Sci. J. Cons. 66:455-461. Article

Urban, J. D.

2015. Discard mortality rates in the Bering Sea snow crab, Chionoecetes opilio, fishery. ICES J. Mar. Sci. 72:15251529. Article

Wassenberg, T. J., and B. J. Hill.

1993. Selection of the appropriate duration of experiments to measure the survival of animals discarded from trawlers. Fish. Res. 17:343-352. Article

Weltersbach, M. S., and H. V. Strehlow.

2013. Dead or alive-estimating post-release mortality of Atlantic cod in the recreational fishery. ICES J. Mar. Sci. 70:864-872. Article

Yergey, M. E., T. M. Grothues, K. W. Able, C. Crawford, and K. DeCristofer.

2012. Evaluating discard mortality of summer flounder
(Paralichthys dentatus) in the commercial trawl fishery: developing acoustic telemetry techniques. Fish. Res. 115-116:72-81. Article

Yochum, N.

2016. Evaluating the efficacy of predicting bycatch mortality using reflex impairment through an assessment of crab discards. Ph.D. diss., 184 p. Oregon State Univ., Corvallis, OR.

Yochum, N., C. S. Rose, and C. F. Hammond.

2015. Evaluating the flexibility of a reflex action mortality predictor to determine bycatch mortality rates: a case study of Tanner crab (Chionoecetes bairdi) bycaught in Alaska bottom trawls. Fish. Res. 161:226-234. Article Yochum, N., A. W. Stoner, D. B. Sampson, C. Rose, A. Pazar, and R. Eder.

2017. Utilizing reflex impairment to assess the role of discard mortality in "size, sex, and season" management for Oregon Dungeness crab (Cancer magister) fisheries. Can. J. Fish. Aquat. Sci. 74:739-750. Article

Zhang, Z., W. Hajas, A. Phillips, and J. A. Boutillier.

2004. Use of length-based models to estimate biological parameters and conduct yield analyses for male Dungeness crab (Cancer magister). Can. J. Fish. Aquat. Sci. 61:21262134. Article 